\title{
RUMPON ATRAKTOR IJUK UNTUK PERIKANAN REKREASI DI KABUPATEN ACEH JAYA PROVINSI ACEH
}

\section{FISH AGGREGATING DEVICES USING PALM FIBER ATTRACTORS FOR RECREATIONAL FISHERIES IN ACEH JAYA ACEH PROVINCE}

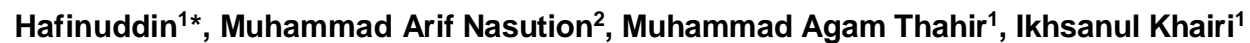 \\ ${ }^{1}$ Program Studi Perikanan, Fakultas Perikanan dan IImu Kelautan, Universitas Teuku Umar \\ 2Program Studi Sumber Daya Akuatik, Fakultas Perikanan dan IImu Kelautan, Universitas Teuku Umar \\ ${ }^{*}$ Korepondensi: hafinuddin@utu.ac.id
}

\begin{abstract}
ABSTRAK
Penggunaan rumpon tradisional sebagai alat bantu penangkapan ikan jaring insang permukaan dan pancing ulur untuk penangkapan ikan pelagis yang dilakukan oleh mitra kelompok nelayan di Kabupaten Aceh Jaya, menyebabkan biaya operasional/maintenance yang tinggi sehingga keuntungan nelayan cenderung kecil. Selain itu, daun pinang atau daun kelapa semakin sulit untuk diperoleh. Oleh karena itu, teknologi rumpon ijuk diharapkan mampu meningkatkan pendapatan nelayan dan kepuasan bagi masyarakat yang melakukan penangkapan ikan untuk rekreasi (fishing recreation) atau olah raga (fishing sport). Pendekatan dalam penyelesaian permasalahan yang telah dilakukan adalah dengan edukasi, pelatihan dan pedampingan. Kegiatan program kemitraan masyarakat (PKM) ini telah dilakukan mulai bulan Januari-Maret 2020. Luaran kegiatan PKM adalah peningkatan pengetahuan dan ketrampilan bagi masyarakat nelayan. Selain itu, diharapkan kualitas teknologi yang diterapkan (rumpon ijuk) dapat lebih baik dari rumpon tradisional dan pendapatan nelayan untuk perikanan rekreasi dapat meningkat.
\end{abstract}

Kata Kunci: rumpon ijuk, Arenga pinnata, FADs, perikanan rekreasi, Kabupaten Aceh Jaya

\section{ABSTRACT}

The traditional fish aggregating devices (FADs) have been assist fishing gear i.e. surface gill nets and hand lines to catching pelagic fish. The traditional FADs have been used by partners of fishermen in Aceh Jaya District and that is increased operational/maintenance costs and decreased fishermen's profits. In addition, areca leaves or coconut leaves are increasingly difficult to obtain. Therefore, the palm fiber FAD technology is expected to be able to increase fishermen's income and satisfaction for community who catch fish for fishing recreation or fishing sport. The approach to solving problems was carried out with education, training and mentoring. This community partnership program (PKM) activity was carried out from January to March 2020. The output of PKM activities is to increasing knowledge and skills for fishing communities. In addition, applied of palm fiber FADs can be better than traditional FADs and can be effect to fisherman's income of recreational fisheries.

Keywords: Palm Fiber Fish Aggregating Devices, Arenga pinnata, FADs, Recreational Fisheries, Aceh Jaya District

\section{PENDAHULUAN Latar Belakang}

Menurut Taquet (2011) dalam Konferensi Internasional di Tahiti "Tuna fisheries and FADs", menjelaskan bahwa penggunaan teknologi rumpon dapat memaksimalkan hasil tangkapan. Selain itu, Taquet (2011) juga menjelaskan bahwa program rumpon (Fish aggregating device/FAD) memiliki manfaat seperti 1) meningkatkan efiseinsi penangkapan; 2) meningkatkan catch per unit effort (CPUE); 3) meminimumkan biaya penangkapan (terutama bahan bakar minyak). 
Komponen rumpon terdiri dari pelampung (float), tali (rope), pengumpul ikan (attractor) dan pemberat (anchor). Altinagac et al. (2010) menjelaskan bahwa atraktor merupakan salah satu komponen utama pada rumpon karena berfungsi sebagai alat pengumpul ikan sesungguhnya.

Hasil penelitian Baihaqi (2014) menunjukkan produktivitas hasil tangkapan atraktor ijuk yang cenderung sama dengan daun kelapa, namun daya tahan atraktor ijuk lebih baik dari daun kelapa dengan masa perendaman yang sama di laut (Baihaqi, 2014). Hasil penelitian Yusfiandayani (2004) menjelaskan bahwa daya tahan dari atraktor daun kelapa adalah 3-4 minggu, sedangkan daya tahan rumpon adalah 3-4 bulan. Sedangkan menurut lbrahim et al. (2014) atraktor daun kelapa hanya mampu bertahan 3 bulan perendaman di laut.

Nelayan jaring insang permukaan di Kabupaten Aceh Jaya menggunakan rumpon tetap (anchor fish aggregating devices/AFADs) dengan menggunakan atraktor daun kelapa atau daun pinang. Modifikasi material untuk alat bantu penangkapan ikan rumpon sangat penting dilakukan. Hal ini agar daya tahan atraktor mampu ditingkatkan sehingga biaya perawatan (maintenance) dari rumpon akan berkurang dan akan menguntungkan bagi nelayan jaring insang permukaan.

Hafinuddin dan Mahendra (2016) menyebutkan bahwa rumpon atraktor ijuk memberikan nilai ekonomis yang lebih tinggi dibandingkan dengan rumpon dengan atraktor yang menggunakan daun kelapa atau daun pinang. Hal ini dikarenakan biaya perawatan rumpon atraktor ijuk lebih kecil dari rumpon atraktor daun pinang atau daun kelapa.

Selain itu, Ibrahim et al. (1996) menjelaskan bahwa lama perendaman atraktor akan berpengaruh terhadap jumlah ikan yang akan berkumpul di sekitar rumpon. Hal ini disebabkan karena periode perendaman akan menstimulus hadirnya organisme akuatik sehingga ketersediaan makanan di sekitar rumpon cenderung akan semakin meningkat.

Kondisi mitra yang masih menggunakan atraktor daun kelapa atau daun pinang telah memberikan biaya operasional (maintenance) yang tinggi yaitu dengan biaya per 3 bulan adalah $\mathrm{Rp} 1.000 .000$ - 1.500.000. Kondisi mitra yang sangat membutuhkan teknologi material baru untuk bahan atraktor rumpon sehingga pengadobsian teknologi tepat guna dan ramah lingkungan adalah kebutuhan yang tidak bisa ditunda lagi.

Mitra kelompok nelayan yang dipilih adalah kelompok nelayan yang berada di Desa Pulo Raya Kecamatan Setia Bakti Kabupaten Aceh Jaya, yang selama ini melakukan penangkapan ikan pelagis dengan menggunakan alat tangkap jaring insang permukaan dan alat bantu penangkapan rumpon atraktor daun alami yaitu daun pinang/daun kelapa.

\section{Masalah}

Beberapa permasalahan mitra/nelayan jaring insang permukaan dengan alat bantu rumpon atraktor daun pinang atau daun kelapa antara lain: (1) alat bantu penangkapan ikan rumpon atraktor daun pinang atau daun kelapa mengakibatkan biaya operasional tinggi, (2) kurangnya informasi bahan pengganti rumpon atraktor daun pinang atau daun kelapa untuk penangkapan ikan pelagis ekonomis penting dengan alat tangkap jaring insang permukaan, (3) masih sangat bergantungnya mitra/nelayan pada atraktor daun pinang atau daun kelapa sehingga biaya investasi yang dikeluarkan cenderung besar, (4) armada penangkapan ikan motor tempel dengan ukuran kapal $<12 \mathrm{~m}$ sehingga nelayan lebih banyak tidak dapat melaut terutama ketika musim peralihan timur-barat. 


\section{METODE}

Penerapan rumpon atraktor ijuk sebagai alternatif teknologi alat bantu penangkapan jaring insang permukaan telah dilakukan dengan pendekatan edukasi, pelatihan dan pendampingan (Hafinuddin dan Hasanah, 2017; Hafinuddin dan Edwarsyah, 2017). Adapun tahapan yang dilakukan dalam kegiatan pengabdian kepada masyarakat nelayan jaring insang permukaan adalah sebagai berikut:

1) Edukasi dan pendampingan mengenai rumpon atraktor ijuk dan alternatif alat tangkap lainnya kepada anggota kelompok nelayan mitra. Kegiatan dilakukan dalam bentuk diskusi interaktif langsung kepada anggota kelompok nelayan mitra dengan tujuan membuka wawasan mengenai rumpon atraktor ijuk dan alat tangkap lain yang dapat digunakan di sekitar rumpon;

2) Pelatihan pembuatan rumpon atraktor ijuk meliputi:

1. Penyiapan alat dan bahan pembuatan rumpon atraktor ijuk dan alat tangkap alternatif seperti pancing ulur;

2. Penentuan daerah pemasangan rumpon atraktor ijuk yang tepat;

3. Pembuatan rumpon atraktor ijuk dan alat tangkap alternatif seperti pancing ulur dan

4. Pengoperasian alat tangkap jaring insang dan pancing ulur di sekitar rumpon atraktor ijuk.

Kegiatan program kemitraan masyarakat ini melibatkan langsung anggota kelompok mitra mulai dari penyiapan alat dan bahan yang digunakan, teknik pembuatan alat tangkap, proses penentuan daerah tangkapan (fishing ground) dan teknik pemasangangan rumpon ijuk di perairan. pengoperasian alat tangkap. Pendampingan kegiatan tetap dilakukan untuk memastikan kegiatan dapat berjalan sebagaimana yang diharapkan.

\section{HASIL DAN PEMBAHASAN}

Kegiatan pengabdian kepada masyarakat yaitu rumpon atraktor ijuk untuk perikanan rekreasi terdiri atas:

1) Penentuan lokasi pemasangan rumpon

Rumpon yang dipasang berjumlah 3 unit yaitu 2 unit rumpon atraktor ijuk dan 1 unit atraktor daun kelapa. Lokasi pemasangan rumpon atraktor ijuk dan atraktor daun kelapa berada pada kedalaman 15-25 meter atau berjarak 2 mil dari PPI Pulo Raya, Kabupaten Aceh Jaya. Substrat dasar laut adalah lumpur berpasir.

2) Pembuatan kerangka atraktor ijuk

Atraktor ijuk terbuat dari besi hallow galvanis adalah dengan panjang 3 meter, lebar 3 meter dan tinggi 3 meter. Luas atraktor ijuk yang berbentuk prima tegak segi empat adalah $27 \mathrm{~m}^{3}$. 
Kerangka atraktor kemudian dilapisi dengan ijuk sehingga bagian/sisi-sisi dari besi akan tertutupi dengan ijuk. Selain itu, antara satu sisi rangka dengan lainnya dipasang tali dari serat ijuk.

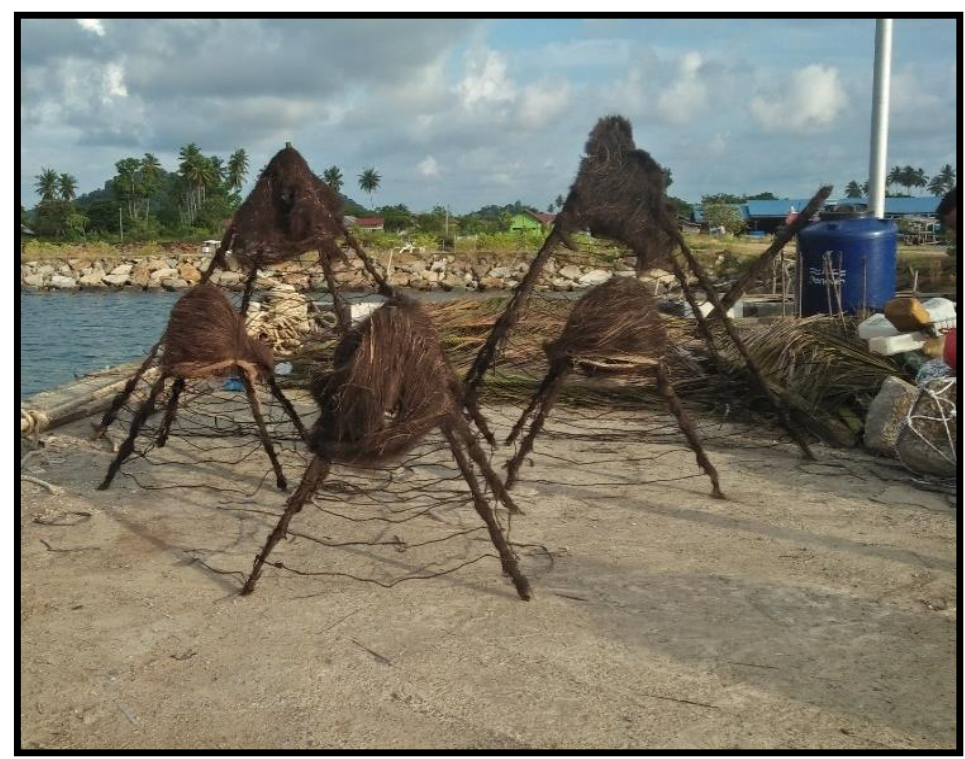

Gambar 1. Rumpon atraktor ijuk untuk perikanan rekreasi.

3) Pemasangan (setting) rumpon ijuk di perairan laut dangkal

Rumpon ijuk sebanyak 3 unit telah dipasang di Perairan Kuala Tadu. Lokasi setting rumpon ijuk berada pada jarak 3 mil dari PPI Kuala Tadu dengan lama tempuh dari fishing base adalah 1 jam dan kedalaman perairan di lokasi pemasangan rumpon adalah 20-30 meter. Selain pemasangan rumpon ijuk, juga dilakukan pemasangan rumpon daun kelapa sebanyak 3 unit, dimana 1 unit rumpon daun kelapa menggunakan 50 pelepah kelapa.
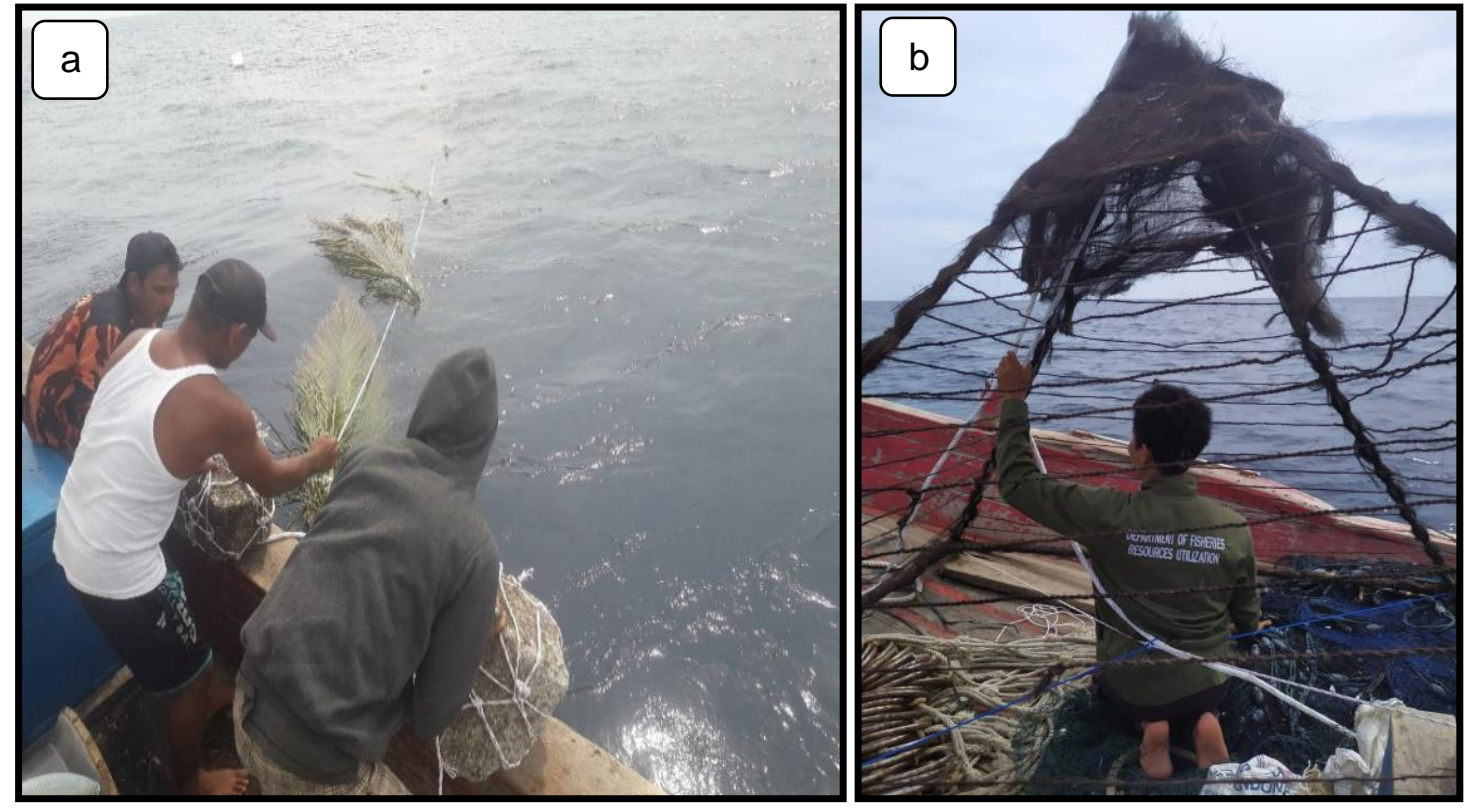

Gambar 2. Peletakan rumpon di Perairan Aceh Jaya: a) Rumpon atraktor daun kelapa dan b) Rumpon atraktor ijuk. 
4) Penangkapan ikan di sekitar rumpon

Penangkapan ikan di sekitar rumpon ijuk dan rumpon daun kelapa menggunakan pancing ulur dan jaring insang dasar serta jaring insang permukaan. Penangkapan dengan pancing ulur atau pancing ramet menggunakan mata pancing yang memiliki bulu-bulu plastik. Selain menggunakan pancing ulur, alat tangkap yang dioperasikan di sekitar rumpon adalah jaring insang permukaan.

Ikan yang tertangkap pada rumpon atraktor daun kelapa antara lain ikan rambai (Carangoides caeruleopinnatus), ketambak (Lutjanus rivulatus), ikan selar ekor kuning (Selarodes leptolepis), ikan selar kuning jantan (Selar boops), ikan lemuru (Sardinella lemuru), ikan selar tetengkek (Megalaspis cordyla), ikan sarden (Sardina pilchardus) dan selar bentong (Selar crumenophthalmus).

Hasil tangkapan bernilai ekonomis penting yang tertangkap pada rumpon atraktor ijuk dan daun kelapa antara lain ikan rambai (Carangoides caeruleopinnatus), ketambak (Lutjanus rivulatus), ikan selar ekor kuning (Selarodes leptolepis), ikan selar kuning jantan (Selar boops), ikan lemuru (Sardinella lemuru), ikan kembung laki - laki (Rastrelliger kanagurta), ikan blidang (Chirosentrus dorab) dan ikan selar tetengkek (Megalaspis cordyla).
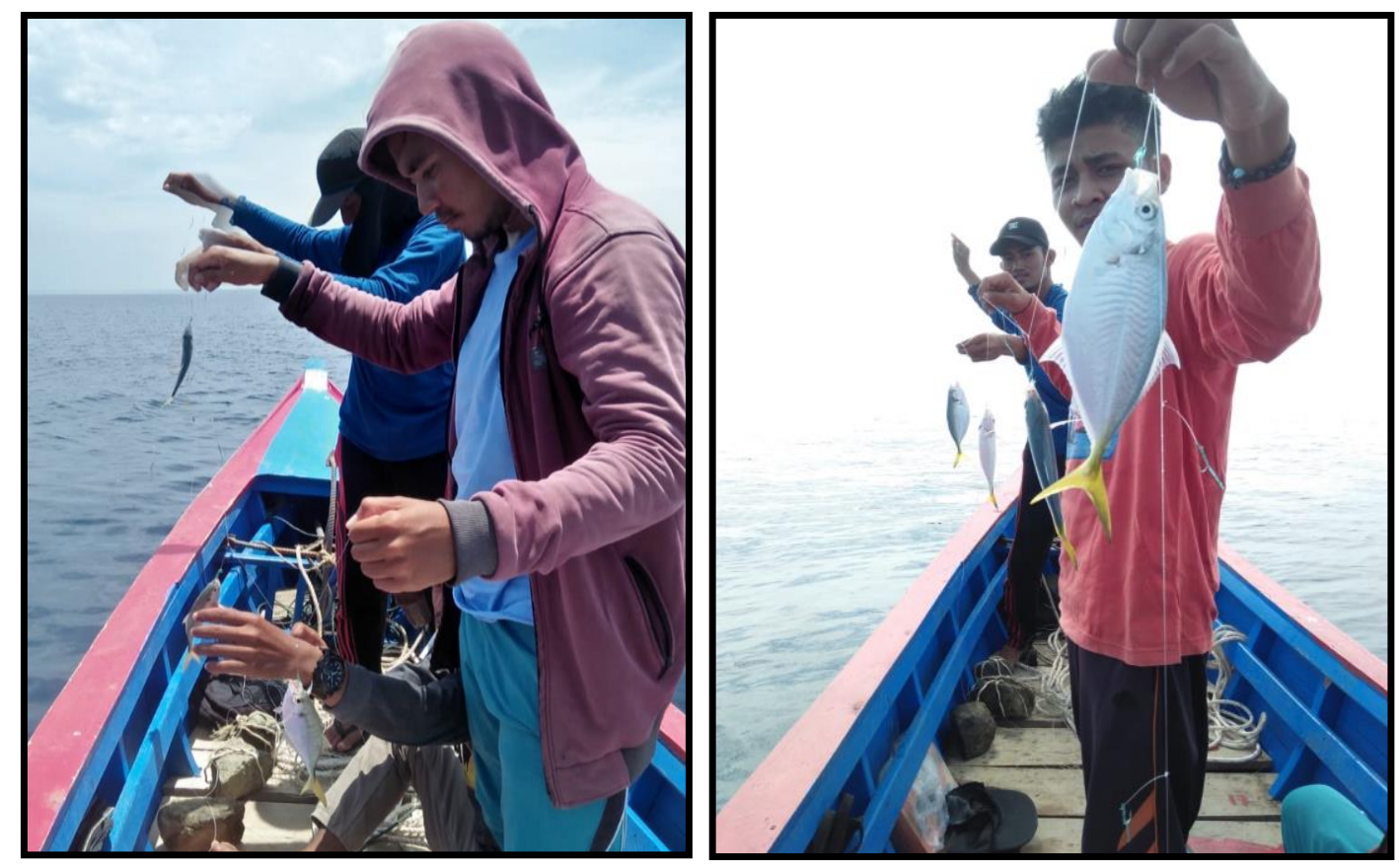

Gambar 3. Kegiatan penangkapan ikan di sekitar rumpon di Perairan Aceh Jaya.

\section{PENUTUP}

Pengabdian PKM pemanfaatan rumpon atraktor ijuk (Arenga pinnata) bagi nelayan jaring insang permukaan di Kecamatan Setia Bakti Kabupaten Aceh Jaya telah dilaksanakan dalam sejumlah kegiatan meliputi edukasi tentang rumpon atraktor ijuk, survei awal lokasi pemasangan rumpon atraktor ijuk, peletakan rumpon daun kelapa sebagai rumpon kontrol untuk pemasangan rumpon ijuk, pelatihan pembuatan atraktor ijuk dan pemasangan rumpon atraktor ijuk serta uji penangkapan ikan di sekitar rumpon ijuk. Kegiatan PKM ini diharapakan dapat berkelanjutan menjadi sebuah usaha yang menguntungkan (profitable) bagi nelayan. 


\section{UCAPAN TERIMA KASIH}

Ucapan terima kasih disampaikan kepada:

1) Lembaga Penelitian dan Pengabdian Masyarakat dan Penjaminan Mutu Umar melalui hibah internal Universitas Teuku Umar skim Pengabdian Berbasis Riset (PBR).

2) Nelayan perintis jaring insang permukaan di Gampong Pulo Raya Kecamatan Setia Bakti Kabupaten Aceh Jaya sebagai pihak mitra.

3) Aparatur Gampong Pulo Raya Kecamatan Setia Bakti Kabupaten Aceh Jaya yang telah memberikan ijin dan memfasilitasi kegiatan ini.

4) Mahasiswa Prodi Perikanan Fakultas Perikanan dan IImu Kelautan Universitas Teuku Umar yaitu Abdul Karim, Iyan Al Misbah, Muhammad Fadhli yang telah banyak membantu kegiatan ini.

\section{DAFTAR PUSTAKA}

Baihaqi, L. I. 2014. Perbandingan karakteristik ikan pada rumpon dengan atraktor ijuk dan atraktor daun kelapa di Perairan Pulau Tunda Banten. Skripsi [Tidak dipublikasikan]. Departemen Pemanfaatan Sumberdaya Perikanan Fakultas Perikanan dan IImu Kelautan Institut Pertanian Bogor. Bogor.

Hafinuddin \& Edwarsyah. 2017. Teknologi penangkapan rajungan (Portunus pelagicus spp.) ramah lingkungan dengan bubu kubah di Kabupaten Aceh Barat Provinsi Aceh. Marine Kreatif, 1 (1): 1-7.

Hafinuddin \& Hasanah, U. 2017. Penerapan perangkap lipat (traps) untuk penangkapan kepiting bakau (Scylla sp.) di Kabupaten Aceh Barat Provinsi Aceh. Marine Kreatif, 1(1): 30-36.

Hafinuddin \& Mahendra. 2016. Pemanfaatan ijuk (Arenga pinnata) sebagai alternatif natural atraktor pada rumpon laut dangkal Perairan Meulaboh Kabupaten Aceh Barat. Laporan Tahun Terakhir Penelitian Dosen Pemula. Universitas Teuku Umar. Meulaboh.

Ibrahim, S., Ambak, M. A., Shamsudin, L. \& Samsudin, M. 1996. Importance of fish aggregating devices (FADs) as subtrates for food organisms of fish. Fisheries Research, 27(4), 265-273.

Ibrahim, S., Hasaruddin, H., Hussin W. M. R. W. \& Ahmad W. M. A. W. 2014. Durability of coconut fronds as attractors for fish aggregating devices (FADs): an observation based on leaf epidermis structure. AACL Bioflux, 7(3), 225-233.

Taquet, M. (2011, September). Artisanal and industrial FADs: A question of scale. SPC Fisheries Newsletter, 136(December), 35-45. Retrieved from http://www.spc.int/coastfish/en/publications/bulletins/fisheriesnewsletter/399- spc-fisheries-newsletter-136.html

Yusfiandayani, R. 2004. Study on the aggregation mechanism of small pelagic fish around rumpon and its fisheries of development in Pasauran Waters, Province of Banten. Unpublished doctoral's thesis, Bogor Agricultural University, Bogor, Indonesia. 